\title{
Pattern of Poisoning In Upper Egypt (Ministry of Justice): Retrospective, Epidemiological Study from 2005 to 2010
}

\author{
Heba A. Yassa', Safaa M. George', Nady S.Ali Abd Eldaim² and Fahd A. \\ Mohammed²
}

\author{
${ }^{1}$ Forensic and Clinical Toxicology Department, Faculty of Medicine, Assiut University \\ ${ }^{2}$ Assiut Forensic Medicine Institute \\ Assiut, Egypt \\ All rights reserved.
}

\begin{abstract}
Poisoning is a great problem affecting people in the all age stages and may lead to death, disease or disability, which may continue throughout the life. Methods: Retrospective study in the Forensic Medicine Laboratory Institute in Upper Egypt from 2005 to 2010. Age, sex, residence and type of poisons were analyzed to determine the toxicity pattern in this area. Results: the study revealed that the toxicity is more common in males than females $(62.5 \%$ and $37.5 \%$ respectively). Age distribution of toxicity is $(30-<40 \mathrm{y})$ followed by $(20-<30 \mathrm{y})(34.83 \%$ and $34.22 \%$ respectively). The most common toxins spread in Upper Egypt is Pesticides toxicity (25\%), and drug of abuse $(22.96 \%)$. Conclusion: Pesticides exposure and drug abuse are two big problems in our community. Drug abuse is a growing problem should be dealt with quickly because it affects the youth group.
\end{abstract}

Keywords Poisoning, drug abuse, pesticides

\section{Introduction}

Poison is a substance capable of producing damage or dysfunction in the body by its chemical activity. It can enter the body in various ways to produce general or local effects. Poisoning is a qualitative term used to define the potential of a chemical substance in acting adversely or deleteriously on the body (Pokhrel et al., 2008).

Poisoning is now a worldwide problem. Increased tendency to use synthetic chemicals and over the counter drugs has resulted in a significant rise in toxicity in all countries (Ghaznawi et al., 1998; Chen et al., 2010). Acute chemical poisoning is a major public health concern. The World Health Organization estimates that total number of acute unintentional poisonings throughout the world ranges from 3.5-5.0 million cases annually, of which 3 million severe poisonings are resulting in 20,000 deaths annually, while the estimated annual intentional poisonings number 2 million resulting in 200,000 suicides (Moazzam et al., 2009).

Exposure to chemicals can be accidental or iatrogenic in young children, whereas it is usually deliberate among adults. The increased tendency to use over-the-counter drugs has resulted in a significant rise in the numbers of patients admitted to hospital suffering from overdose. Intentional self-poisoning is a major problem worldwide. In industrial countries, it predominantly occurs in young people impulsively responding to stressful events who have little desire to die (Eddleston et al., 2005).

The WHO estimates, based on 2001 data, that 849,000 people die globally from self-harm each year (WHO, 2002). A review of poisoning studies reveals that pesticides are the commonest means of selfpoisoning in many rural areas and associated with a high mortality rate (Eddleston et al., 2002).

The epidemiological properties differ from one country to country and from community to community in the same country. Thus, a special and periodical surveillance for each country is necessary to through light on the magnitude of the problem in order to establish the necessary preventive and management policies (Gamaluddin, 2004). In most cases, poisoning occurs in the home, is acute and accidental, and 
involves children under the age of 6 years. Personal care products (e.g., cosmetics, creams, lotions, mouthwash), household cleaning products and chemicals (e.g., pesticides), and over-the-counter or prescription medications (e.g., pain relievers, cough and cold medicines, vitamins) are common causes for acute childhood poisoning. Some types of childhood poisoning develop over time, due to repeat or chronic (i.e., long-lasting) exposure to small amounts of the toxic substance. Lead poisoning, which is more common in young children and can cause serious neurological damage, usually develops slowly over time when a child is exposed to lead. According to the American Association of Poison Control Centers, approximately 1.5 million cases of poisoning occur in children and adolescents under the age of 20 each year in the United States. More than $50 \%$ of all poisonings occur in children under the age of 6 years. Peak incidence of childhood poisoning occurs between 1 and 3 years of age (Stanley and Swierzewski, 2008).

\section{Aim of the study is to:}

(1) Determine the toxicity pattern in Upper Egypt as regard age, sex, residence and type of toxin.

(2) Investigate the most common type of toxicity among people live in Upper Egypt.

(3) Compare most common type of poison among male and female victims.

\section{Type of the study: retrospective study}

\section{Subjects and Method}

\section{Data collection}

Demographical data on toxicity cases (dead or alive) numbers, age, sex, residence (urban or rural), were collected retrospectively from the Forensic Medicine laboratory Institute, Ministry of Justice, in Upper Egypt during the period from 2005 to 2010.

The Forensic Medicine Laboratory Institute reports included full toxicological analysis, to differentiate between positive and negative cases.

The study was carried out in Upper Egypt which is a narrow strip of land that extends from the cataract boundaries of modern-day Aswan to the area between El-Aiyat and Zawyet Dahshur, south of modern-day Cairo (www.wikepedia.com; www.en.wikipedia.org/wiki/Governorates_of_Egypt).

All query cases of toxicity in Upper Egypt studied by the Forensic Medicine Laboratory Institute and differentiated into positive and negative cases, these cases conversed to the toxicology laboratory from the forensic medicine authority (Ministry of Justice) to prove toxicity as a cause of death, or in case of motorcar accidents to prove toxicity of the drivers .
Then all positive cases were studied to determine the causative agents.

Ethical considerations in the research according to the rules of Assiut University were followed, as no data about the names of the cases were mentioned in the research.

\section{Statistical analysis}

Collected data was expressed as percentage and sorted according to age group, sex, residence (urban - rural), and collected samples (blood - urine - stomach washviscera - bottles - and vomit), toxins detected among the positive cases. Chi - square test was carried out using SPSS program version 15.

\section{Results}

Studied toxicological cases in the period from 2005 to 2010 and the percent of positive cases are shown in table (1) and figure (1). This table and figure show all studied cases of suspected toxicity in the period from 2005 to 2010 in Upper Egypt which was 1709 cases, 488 cases were positive cases $(28.55 \%)$. Figure (2) and table (2) show the percent of dead and live cases in the positive toxicity cases in the same area and same period, it shows that toxicity as a cause of death is more common in the studied period. Table (3) age distribution in the positive toxicity cases, it shows that the cases was concentrated in the middle age group (30 - $\leq 40$ years) $34.83 \%$ followed by the age group (20 - $\leq$ 30 years) $34.2 \%$. Table (4) and figure (3) show that toxicity in male more than in female $(62.5 \%, 37.5 \%$ respectively).

Table (5, and 6) show the distribution of toxicity cases in urban and rural areas, they show that there was a significant increase in the toxicity cases in urban areas if compared with those in rural areas (83.4\%, $16.6 \%$ respectively). Table (6) shows the difference in toxicity cases among the different urban areas, Assiut, Sohag, El Minia, New Valley, Luxor, Aswan, Qena and Red Sea cities (31.1\%, 15.7\%, 9.5\%, $2.7 \%, 2.7 \%, 4.7 \%, 15 \%, 2.3 \%$ respectively)

Table (7) pattern of toxins detected among the positive toxicity cases, it shows that the most common toxins studied in the period from 2005 to 2010 is organophosphate and carbamate $(25 \%)$, followed by drug abuse $(22.96 \%)$ and ethyl alcohol toxicity $(20.5 \%)$, then hair dyes $(14.3 \%)$.

Table (8) samples studied in analysis process for toxins, it shows that the most common sample to the laboratory was viscera from dead victims (46.7\%), followed by blood from live victims and bottle samples in both dead and live victims $(13.3 \%$, and $13.3 \%)$ then stomach wash from live victims $(11.5 \%)$. 
Table (1): Distribution percentage of all studied cases in the period from 2005 to 2010.

\begin{tabular}{|l|c|c|c|}
\hline Year & No of all cases & No of positive cases & $(\mathbf{\%})$ \\
\hline 2005 & 251 & 84 & 33.5 \\
\hline 2006 & 333 & 119 & 35.7 \\
\hline 2007 & 263 & 65 & 24.7 \\
\hline 2008 & 265 & 68 & 25.6 \\
\hline 2009 & 290 & 69 & 23.8 \\
\hline 2010 & 307 & 83 & 27 \\
\hline Total & 1709 & 488 & 28.55 \\
\hline
\end{tabular}

Table (2): Dead and live cases studied in the period from 2005 to 2010.

\begin{tabular}{|c|c|c|c|c|c|c|}
\hline \multirow{2}{*}{ Year } & \multicolumn{2}{c|}{ Dead } & \multicolumn{2}{c|}{ Live } & \multicolumn{2}{c|}{ Total } \\
\cline { 2 - 7 } & No & \% from total positive cases & No & \% from total positive cases & No. & \% \\
\hline 2005 & 41 & 8.4 & 43 & 8.8 & 84 & 17.2 \\
\hline 2006 & 74 & 15.2 & 45 & 9.3 & 119 & 24.5 \\
\hline 2007 & 29 & 5.9 & 36 & 7.4 & 65 & 13.3 \\
\hline 2008 & 34 & 6.9 & 34 & 6.9 & 68 & 13.8 \\
\hline 2009 & 28 & 5.7 & 41 & 8.4 & 69 & 14.1 \\
\hline 2010 & 53 & 10.9 & 30 & 6.2 & 83 & 17.1 \\
\hline Total & 259 & 53 & 229 & 47 & 488 & 100 \\
\hline
\end{tabular}

Table (3): Age distribution in the positive toxicity cases in the period from 2005 to 2010 (descriptive frequency test).

\begin{tabular}{|l|c|c|c|c|c|c|c|c|}
\hline Year & \multirow{2}{*}{$\mathbf{2 0 0 5}$} & \multirow{2}{*}{$\mathbf{2 0 0 6}$} & \multirow{2}{*}{$\mathbf{2 0 0 7}$} & \multirow{2}{*}{$\mathbf{2 0 0 8}$} & \multirow{2}{*}{$\mathbf{2 0 0 9}$} & \multirow{2}{*}{$\mathbf{2 0 1 0}$} & \multicolumn{2}{|c|}{ Total } \\
\cline { 3 - 10 } & & & & & & No. & \% \\
\hline $0-<10$ years & 1 & 0 & 0 & 0 & 3 & 1 & 5 & 1.02 \\
\hline $10<20$ years & 7 & 9 & 2 & 1 & 1 & 20 & 40 & 8.19 \\
\hline $20-<30$ years & 29 & 34 & 27 & 26 & 27 & 24 & 167 & $34.22^{* *}$ \\
\hline $30-<40$ years & 26 & 46 & 23 & 29 & 23 & 23 & 170 & $34.83 * *$ \\
\hline $40-<50$ years & 18 & 25 & 8 & 9 & 12 & 14 & 86 & $17.62^{*}$ \\
\hline $50-<60$ years & 3 & 5 & 5 & 3 & 3 & 1 & 20 & 4.09 \\
\hline$>60$ years & 0 & 0 & 0 & 0 & 0 & 0 & 0 & 0 \\
\hline Total & 84 & 119 & 65 & 68 & 69 & 83 & & 488 \\
\hline
\end{tabular}

$P$ value: $*$ significant $<0.005, * *$ highly significant $<0.001$

Table (4): Sex distribution in the positive toxicity cases in the period from 2005- to 2010 (descriptive frequency test).

\begin{tabular}{|l|c|c|c|c|c|}
\hline \multirow{2}{*}{ Year Sex } & \multicolumn{2}{|c|}{ Male } & \multicolumn{2}{c|}{ Female } & Total \\
\cline { 2 - 6 } & No & \% & No & No & 84 \\
\hline 2005 & 49 & 10.04 & 35 & 5.17 & 119 \\
\hline 2006 & 90 & 18.44 & 29 & 5.33 & 65 \\
\hline 2008 & 39 & 7.99 & 26 & 6.15 & 68 \\
\hline 2009 & 38 & 7.79 & 30 & 5.74 & 69 \\
\hline 2010 & 41 & 8.40 & 28 & 7.17 & 83 \\
\hline Total & 48 & 9.84 & 35 & 37.5 & 488 \\
\hline
\end{tabular}

P value: ${ }^{*}$ significant $<0.005$ 
Table (5): Governorates distribution of positive toxicity cases in the period from 2005 - to 2010 (descriptive frequency test).

\begin{tabular}{|c|c|c|c|c|c|c|c|c|}
\hline \multirow{2}{*}{ Residence $\quad$ Year } & \multirow{2}{*}{2005} & \multirow{2}{*}{2006} & \multirow{2}{*}{2007} & \multirow{2}{*}{2008} & \multirow{2}{*}{2009} & \multirow{2}{*}{2010} & \multicolumn{2}{|c|}{ Total } \\
\hline & & & & & & & No & $\%$ \\
\hline Assiut City & 15 & 50 & 17 & 29 & 25 & 16 & 152 & $31.1 *$ \\
\hline Abnoub and Elfath & 2 & 5 & 1 & 1 & 3 & 0 & 12 & 2.5 \\
\hline Sedfa & 0 & 1 & 0 & 0 & 0 & 0 & 1 & 0.2 \\
\hline Abutieg & 1 & 5 & 3 & 0 & 0 & 0 & 9 & 1.8 \\
\hline El-Badary & 0 & 0 & 0 & 0 & 0 & 0 & 0 & 0 \\
\hline Sahel Selim & 0 & 3 & 2 & 0 & 0 & 0 & 5 & 1.1 \\
\hline Manfalout & 2 & 2 & 2 & 1 & 0 & 1 & 8 & 1.6 \\
\hline El-Quosia & 0 & 2 & 1 & 0 & 0 & 0 & 3 & 0.6 \\
\hline Dayrout & 0 & 0 & 0 & 0 & 0 & 0 & 0 & 0 \\
\hline El-Ghanaime & 1 & 0 & 0 & 0 & 0 & 0 & 1 & 0.2 \\
\hline Sohag & 12 & 10 & 13 & 12 & 14 & 15 & 76 & 15.7 \\
\hline Tema/saqulta & 1 & 2 & 0 & 0 & 0 & 0 & 3 & 0.6 \\
\hline Tahta & 2 & 1 & 1 & 3 & 0 & 1 & 8 & 1.6 \\
\hline Gerga & 2 & 0 & 0 & 1 & 0 & 0 & 3 & 0.6 \\
\hline ekhmem & 0 & 1 & 0 & 0 & 0 & 0 & 1 & 0.2 \\
\hline El monshaa and El oseyrat & 0 & 0 & 0 & 0 & 0 & 0 & 0 & 0 \\
\hline El maragha & 0 & 0 & 0 & 0 & 0 & 0 & 0 & 0 \\
\hline Dar el salam & 0 & 0 & 1 & 0 & 0 & 0 & 1 & 0.2 \\
\hline El Minia & 10 & 10 & 8 & 6 & 4 & 8 & 46 & 9.5 \\
\hline Samalot and banymazar & 0 & 1 & 0 & 0 & 0 & 1 & 2 & 0.4 \\
\hline Maghaga & 0 & 0 & 0 & 0 & 0 & 2 & 2 & 0.4 \\
\hline Abu korkas & 1 & 0 & 2 & 0 & 0 & 0 & 3 & 0.6 \\
\hline El adwa & 1 & 0 & 0 & 0 & 0 & 0 & 1 & 0.2 \\
\hline Qena & 1 & 18 & 9 & 8 & 13 & 24 & 73 & 15 \\
\hline Naga Hamady & 0 & 0 & 0 & 0 & 0 & 0 & 0 & 0 \\
\hline Nagada and Farshoot & 0 & 0 & 0 & 0 & 2 & 0 & 2 & 0.4 \\
\hline Kaft and koos & 0 & 0 & 0 & 0 & 0 & 1 & 1 & 0.2 \\
\hline deshna & 0 & 0 & 0 & 0 & 0 & 1 & 1 & 0.2 \\
\hline Luxor & 6 & 0 & 4 & 0 & 0 & 3 & 13 & 2.7 \\
\hline Armant & 0 & 0 & 0 & 0 & 0 & 2 & 2 & 0.4 \\
\hline Aswan & 10 & 0 & 1 & 5 & 3 & 4 & 23 & 4.7 \\
\hline Wady Gaded & 6 & 4 & 0 & 1 & 1 & 1 & 13 & 2.7 \\
\hline Red sea & 5 & 3 & 0 & 1 & 1 & 1 & 11 & 2.3 \\
\hline Orghada & 5 & 0 & 0 & 0 & 0 & 0 & 5 & 1.1 \\
\hline Al koseer & 1 & 1 & 0 & 0 & 3 & 1 & 6 & 1.2 \\
\hline Total & 84 & 119 & 65 & 68 & 69 & 83 & & \\
\hline
\end{tabular}

P value:* significant $<0.005$

Table (6): Urban and rural distribution of positive toxicity cases in the period from 2005 - to 2010 (descriptive frequency test).

\begin{tabular}{|c|c|c|c|c|c|c|c|c|}
\hline \multirow{2}{*}{ Year } & \multirow{2}{*}{2005} & \multirow{2}{*}{2006} & \multirow{2}{*}{2007} & \multirow{2}{*}{2008} & \multirow{2}{*}{2009} & \multirow{2}{*}{2010} & \multicolumn{2}{|c|}{ Total } \\
\hline & & & & & & & No. & $\%$ \\
\hline Urban & 65 & 95 & 52 & 62 & 61 & 72 & 407 & $83.4 * *$ \\
\hline Rural & 19 & 24 & 13 & 6 & 7 & 11 & 81 & 16.6 \\
\hline Total & 84 & 119 & 65 & 68 & 69 & 83 & & \\
\hline
\end{tabular}


Table (7): Toxins detected among positive cases (Chi square analysis).

\begin{tabular}{|c|c|c|c|c|c|c|c|c|}
\hline \multirow{2}{*}{ Toxin $\quad$ Year } & \multirow{2}{*}{2005} & \multirow{2}{*}{2006} & \multirow{2}{*}{2007} & \multirow{2}{*}{2008} & \multirow{2}{*}{2009} & \multirow{2}{*}{2010} & \multicolumn{2}{|c|}{ Total } \\
\hline & & & & & & & No. & $\%$ \\
\hline Alcohol & 15 & 47 & 8 & 6 & 5 & 19 & 100 & $20.5 *$ \\
\hline Ammonium phosphate & 5 & 2 & 3 & 6 & 3 & 1 & 20 & 4.1 \\
\hline Co poisoning & 4 & 1 & 1 & 0 & 3 & 1 & 10 & 2.04 \\
\hline Diazepam & 4 & 0 & 0 & 5 & 1 & 3 & 13 & 2.7 \\
\hline $\mathrm{HCl}$ & 1 & 1 & 0 & 0 & 0 & 0 & 2 & 0.4 \\
\hline Mercury & 1 & 1 & 0 & 0 & 1 & 3 & 6 & 1.2 \\
\hline Organophosphate \& carbamate & 17 & 21 & 25 & 16 & 24 & 19 & 122 & $25 *$ \\
\hline Sulphuric acid & 1 & 2 & 0 & 0 & 0 & 0 & 3 & 0.6 \\
\hline Hair dye & 15 & 17 & 9 & 17 & 12 & 0 & 70 & 14.3 \\
\hline Corrosives & 1 & 0 & 1 & 0 & 0 & 0 & 2 & 0.4 \\
\hline Dexomethicin & 0 & 1 & 0 & 0 & 0 & 0 & 1 & 0.2 \\
\hline Antibiotics & 0 & 0 & 0 & 0 & 3 & 2 & 5 & 1.02 \\
\hline Hydrocarbons & 0 & 2 & 2 & 1 & 4 & 6 & 15 & 3 \\
\hline Methylalcohl & 0 & 1 & 0 & 0 & 2 & 0 & 3 & 0.6 \\
\hline Sodium chloride & 0 & 0 & 1 & 0 & 0 & 0 & 1 & 0.2 \\
\hline Anti hepertensive & 0 & 0 & 0 & 0 & 0 & 1 & 1 & 0.2 \\
\hline Nalophin & 0 & 0 & 0 & 2 & 0 & 0 & 2 & 0.4 \\
\hline Parkinol & 0 & 0 & 0 & 2 & 1 & 0 & 3 & 0.6 \\
\hline Cannabis & 4 & 2 & 6 & 3 & 6 & 6 & 27 & 5.5 \\
\hline Heroin & 5 & 1 & 3 & 3 & 0 & 5 & 17 & 3.5 \\
\hline Tramadol & 6 & 3 & 3 & 6 & 2 & 13 & 33 & 6.8 \\
\hline Benzodiazepins & 0 & 4 & 0 & 1 & 0 & 0 & 5 & 1.02 \\
\hline Carbamezepin & 0 & 10 & 0 & 0 & 0 & 0 & 10 & 2.04 \\
\hline Clonezpam & 0 & 1 & 1 & 0 & 2 & 0 & 4 & 0.8 \\
\hline Tranquilizers & 0 & 0 & 2 & 0 & 0 & 0 & 2 & 0.4 \\
\hline Alkylation material & 5 & 2 & 0 & 0 & 0 & 4 & 11 & 2.3 \\
\hline Drug abuse total (without alcohol) & 20 & 23 & 15 & 15 & 11 & 28 & 112 & $22.96^{*}$ \\
\hline Total & 84 & 119 & 65 & 68 & 69 & 83 & & 8 \\
\hline
\end{tabular}

$P$ value:* significant $<0.005$

Table (8): Samples studied in positive toxicity cases in the period from 2005 to 2010 (Chi square analysis).

\begin{tabular}{|c|c|c|c|c|c|c|c|c|}
\hline \multirow{2}{*}{ Sample $\quad$ Year } & \multirow{2}{*}{2005} & \multirow{2}{*}{2006} & \multirow{2}{*}{2007} & \multirow{2}{*}{2008} & \multirow{2}{*}{2009} & \multirow{2}{*}{2010} & \multicolumn{2}{|c|}{ Total } \\
\hline & & & & & & & No & $\%$ \\
\hline Blood & 16 & 16 & 6 & 7 & 17 & 3 & 65 & 13.3 \\
\hline Vomitus & 1 & 0 & 0 & 0 & 0 & 0 & 1 & 0.2 \\
\hline Stomach wash & 7 & 12 & 9 & 15 & 8 & 5 & 56 & 11.5 \\
\hline Urine & 4 & 3 & 1 & 0 & 14 & 11 & 33 & 6.8 \\
\hline Viscera & 35 & 22 & 38 & 32 & 51 & 50 & 228 & $46.7 * *$ \\
\hline Clothes & 1 & 0 & 1 & 3 & 3 & 2 & 10 & 2 \\
\hline Juice & 1 & 1 & 0 & 2 & 1 & 1 & 6 & 1.2 \\
\hline Meat & 0 & 1 & 0 & 0 & 0 & 0 & 1 & 0.2 \\
\hline Bread & 0 & 0 & 0 & 1 & 0 & 0 & 1 & 0.2 \\
\hline Powder & 0 & 1 & 0 & 0 & 0 & 0 & 1 & 0.2 \\
\hline Tablet & 0 & 1 & 0 & 1 & 0 & 0 & 2 & 0.4 \\
\hline Paste & 0 & 4 & 0 & 0 & 0 & 0 & 4 & 0.8 \\
\hline Bag & 0 & 0 & 2 & 0 & 0 & 3 & 5 & 1.02 \\
\hline Glass & 1 & 1 & 2 & 0 & 6 & 0 & 10 & 2 \\
\hline bottle & 17 & 7 & 9 & 4 & 19 & 9 & 65 & 13.3 \\
\hline Total & 83 & 69 & 68 & 65 & 119 & 84 & & \\
\hline
\end{tabular}

P value: ** highly significant $<0.001$ 

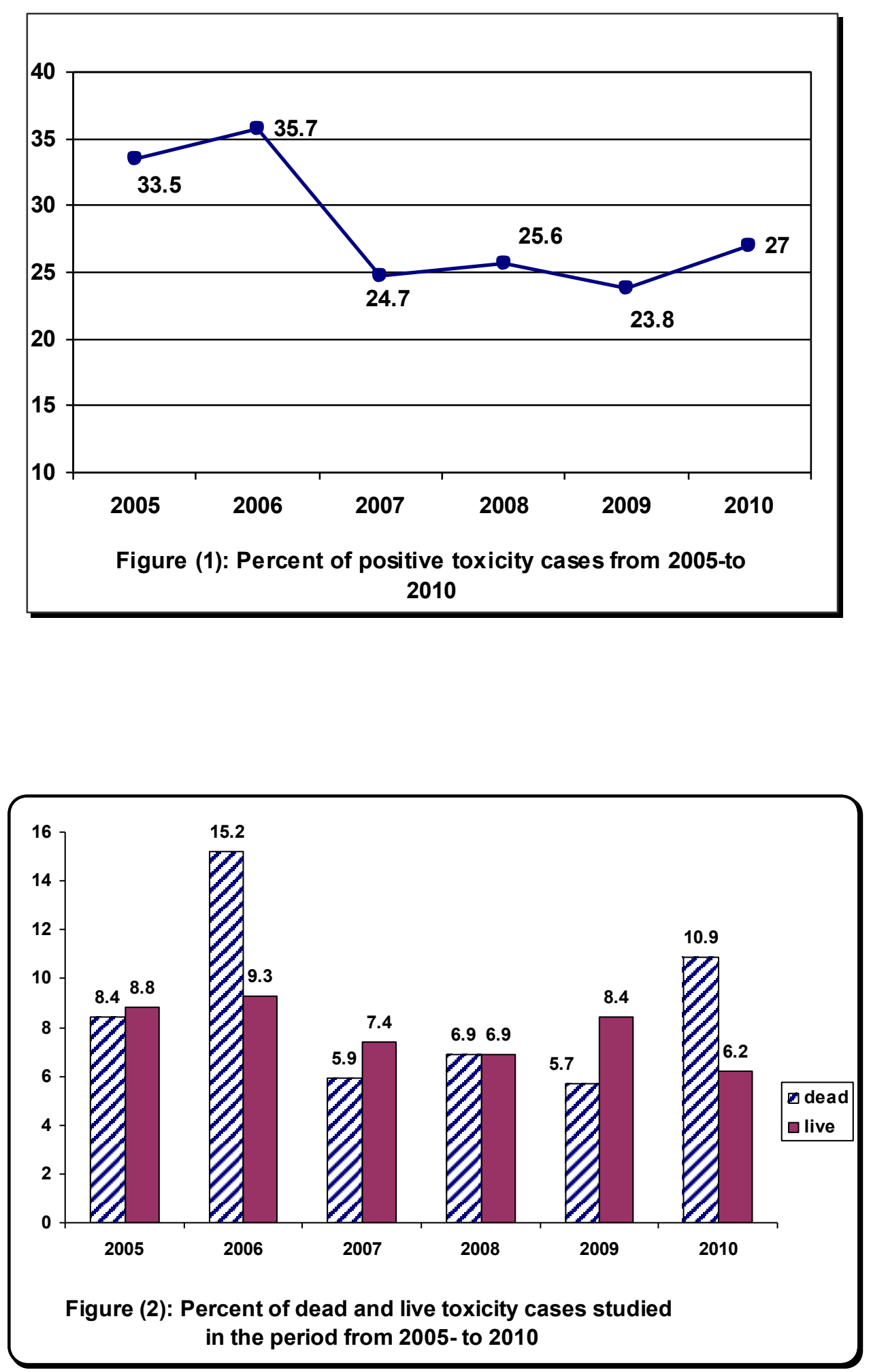


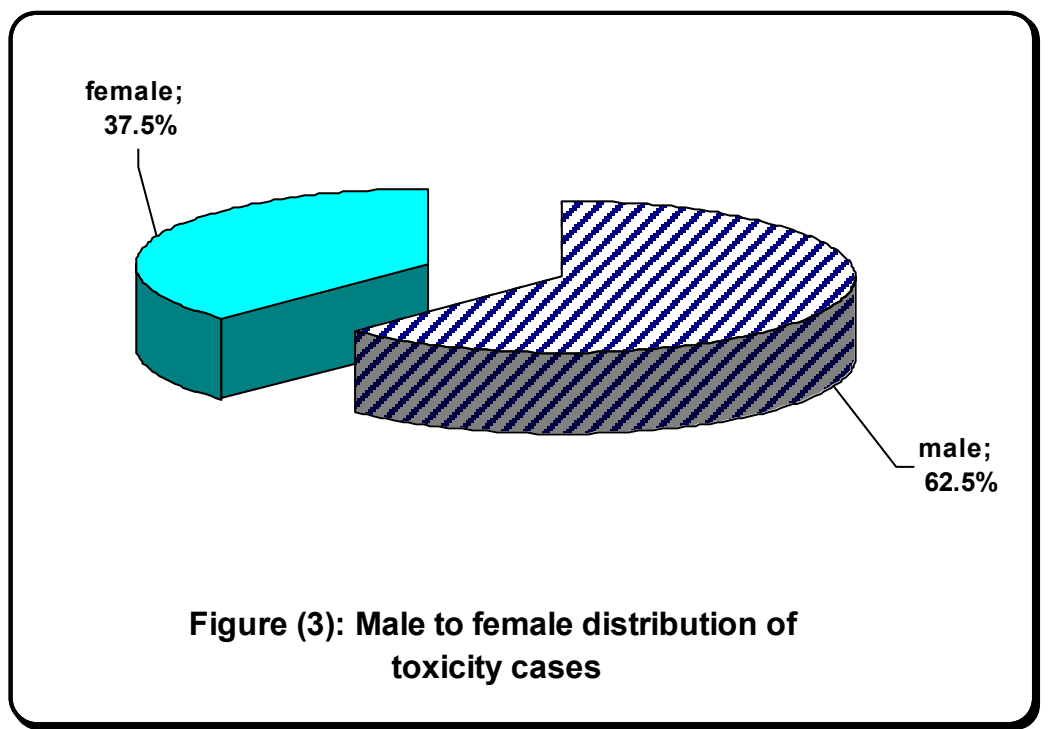

\section{Discussion}

The present study revealed the toxicity pattern in Upper Egypt in the period from 2005 to 2010. Poison become the leading cause of death in the United States in 2008 and nearly 9 out of 10 poisoning deaths are now caused by drugs, according to a December 2011 Centers for Disease Control and Prevention report (Mpiorunski, 2012). In addition, poison is the fourth leading cause of death in Russia. According to the World Health Organization, there are more deaths by poison in Russia than by traffic accidents and 9 out of the top 10 countries in death rate by poison are former members of the Soviet Union (LeDuc, 2012). In Egypt and according to the world health ranking, death due to drugs is the 25th cause of death, but Egypt considers the 17th in the world in death due to drugs (WHO report, 2010).

In the present study, all studied toxicity cases were 1709 , from which $488(28.55 \%)$ were positive. Age distribution for toxicity cases appeared to be distributed in the age group (30 - $<40$ years) followed by $(20-<30$ years) which is the age of work and exposure to occupational toxins, over the counter drugs, drugs of abuse and other environmental toxins. Ghaznawi et al., (1998), in his study about poisoning problem in Jeddah region reported that the most common age of toxicity is the children below 5 years, and explained that by curiosity at this age. On the other hand, Abd - Elhaleem and Abd Elkarim (2011) reported in their study about the food poisoning in Egypt, that the most common age of toxicity is the middle age followed by the school age. This indicates differences between countries in the age distribution of such toxicity. According to the Alabama poisoning center, adult is responsible for about $80 \%$ of poisoning and around $90 \%$ deaths due to poison (www. alapoisoncenter.org).

In the present study, it was found that males are predisposed to poisoning and toxicity than females (62.5\% $-37.5 \%$ respectively). This is due to that male are more exposed to the occupational hazards more than females, Also, male having more tendency to drug abuse more than females. Lee et al., (2012) in agreement with the present results, they found that the incidence of exposure to poison is more common among male than females. Also, the office for National statistics referred that death in male due to drug and poison exposure are more common than females, most deaths in females are intentional or suicide, but for males most cases of poison exposure s due to drug over dose, or occupational poisoning (National Statistics Office, 2010).

Distribution of toxicity cases in the present study followed the distribution of industrial regions, where the poison is more common in urban areas than in rural areas $(83.4 \%-16.6 \%$ respectively). The pattern of poison distribution in the study from 2005 to 2010 also followed the industrial areas where the organophospates and carbamates were the most common toxins found ( $25 \%$ of all positive cases) followed by drug abuse and alcohol $(22.96 \%$ and $20 \%$ respectively) then hair dyes (14.3\%). The National Capital Poison Center showed that the most common poisons among adults in Washington, 2011 were pain relievers, sedatives, hypnotics, and alcohols followed by pesticides, cosmetics and personal care products. These data explained a growing problem in Upper Egypt which is the wide spread of drug abuse and alcohol among the middle age group. Yassa et al., (2009) found that bango (cannabis leaves in Egypt) abuse consider a big problem in Upper Egypt especially in the middle age group. Risk, (2005); World drug report, (2011) reported that the drug abuse is a problem in Egypt need more study because it is becoming a serious problem. Pesticides as a cause of toxicity are an old problem in Egypt, as an unintentional toxicity due to occupational exposure, or as a suicidal cause of toxicity especially in females. Eddleston et al., (2005) reported the same problem of 
pesticides use as a self-poisoning in rural areas of Seri Lanka. In addition, Lee and Cha (2009) reported that the pesticides have a great problem as an occupational cause of toxicity. Hair dyes is a rare cause of death but can be used especially by female for suicidal attempt, or accidentally used by children. Jain et al., (2011) reported in their study hair dye as a cause of death in India and other developing countries, it usually leads to myocarditis or renal failure.

\section{Conclusion}

Toxins play an important role all over the world especially in the third world countries. Pesticides use has increased in recent years, and have many hazards due to their misuse as an occupational toxins, or as self harm poison. Drug abuse considers a very large problem in Egypt, increasing in intensity especially among the youth and middle aged male. These hidden problems must be clarified to the community and try to find a solution, as health educational programs, schools and colleges curricula.

\section{References}

Abd Elhaleem Z, and Abd Elkarim M (2011): Pattern of food poisoning in Egypt, a retrospective study. Journal of Pharmacology and Toxicology 6(5): p $505-515$

Chen F, Wen J, Wang X et al., (2010): Epidemiology and characteristics of acute poisoning treated at an emergency center. World J Emerg Med, Vol 1, No 2 P 154 - 156

Eddleston M, Gunnell D, Karunaratne A et al., (2005): Epidemiology of intentional self-poisoning in rural Sri Lanka. The British Journal of Psychiatry 187: 583-584

Eddleston M, Karalliedde L, Buckley N et al., (2002): Pesticide poisoning in the developing worldaminimum pesticide list. Lancet 12, 11631167.

Gamaluddin H A (2004): The magnitude of the poisoning problem in Cairo: an overview. 1st International Conference on Natural Toxins October 6 University - Egypt 18 - 19 December 2004.

Ghaznawi H, Gamal-Eldin H, and Khalil A (1998): Poisoning problem in Jeddah region. Annals of Saudi Medicine, Vol 18, No 5 P $460-462$

Jain P, Agarwal N, Sharma Kr A et al., (2011): Prospective study of ingestional hair dye poisoning in Northern India (Prohina). Journal of Clinical Medicine and Research Vol. 3(1) p. 9-19

LeDuc T (2012): Is Russia poisoning her people? www.worldlifeexpectancy.com accessed in may 2012

Lee W and Cha E (2009): Overview of Pesticide Poisoning in South Korea. J Rural Med; 4(2): 53-58
Lee WJ, Cha ES, Park J et al., (2012): Incidence of acute occupational pesticide poisoning among male farmers in South Korea. Am J Ind Med. 2012 Feb 21. doi: 10.1002/ajim.22024

Moazzam M, Al-Saigul A, Naguib M et al., (2009): Pattern of acute poisoning in Al- Qassim region: a surveillance report from Saudi Arabia, 1999-2003. Eastern Mediterranean Health Journal, Vol. 15, No. 4, p 1005 - 1010

Mpiorunski B (2012): Poisonings a Leading Cause of Death, Poison Prevention Week Celebrates 50. http:// www.migrantclinician.org/ blog/2012/ mar/poisonings- leading-causedeath- poison-prevention-week- celebrates50.html. Accessed in May 2012.

National Capital Poison Center (2011): Poisoning statistics. http://www.poison.org/stats/ accessed in May 2012.

National Statistics Office NSO (2010): Drug poisoning deaths fall for males but not for females. http://www. ons.gov.uk/ons/dcp29904_ 230777. pdf. accessed May 2012.

Pokhrel D, Pant S, Pradhan A., (2008): A copparative retrospective study of poisoning cases in Central, Zonal, and District hospitals. Kathmandu university journal of science, engineering and technology vol. I, No. V, pp $40-48$.

Risk A (2005): Drug Abuse: A challenge to education - Egypt. http:// www. eenet.org.uk/ resources/eenet_newsletter/ news9/page3.php. Accessed in May 2012.

Stanley J and Swierzewski III (2008): Poisoning Overview, Incidence and Prevalence. http://www. healthcommunities. Com /poisoning /overview-of-poisoning.shtml accessed in May 2012.

WHO "world health organization" (2002): The World Health Report 2002. Reducing Risks, Promoting Healthy Life. WHO, Geneva.

WHO world health organization report (2010): http://www.worldlifeexpectancy.com/countryhealth-profile/egypt? Accessed in May 2012.

World Drug Report (2011): United Nations Office on Drugs and Crimes. http:// www.unodc.org/ documents/data-and-analysis/ WDR2011/ World_Drug_Report_2011_ebook.pdf

www. alapoisoncenter. org/ph_different_age groups .htm: Poisoning are problems for every one. Accessed in May 2012.

www. Wikipedia.com; www. en.wikipedia.org/wiki/Upper_Egypt. Accessed in May 2012.

Yassa H, Dawood A, Shehata M et al., (2009): Risk factors of bango abuse in Upper Egypt. Environ Toxicol Pharmacol. Nov; 28(3):39740 


\section{الملخص العربي}

\section{نمط التسمم في صعيد مصر دراسة مرجعية في الفترة من 2005 إلى 2010 \\ هبة عطية يسي 1 و صفاء ماهر جورج1 و نادي سيد علي عبد الدايم² و فهز عبد العظيم محمد2}

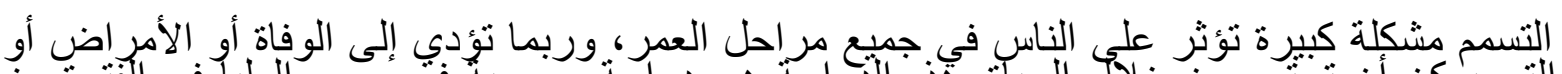

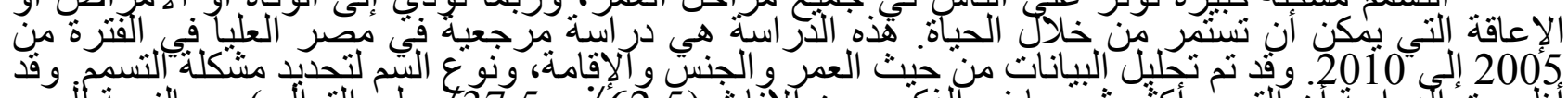

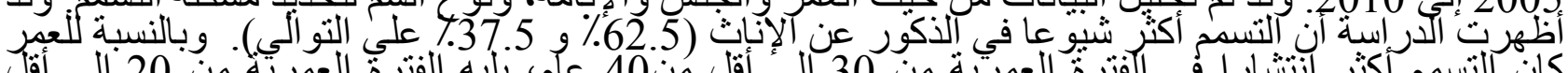

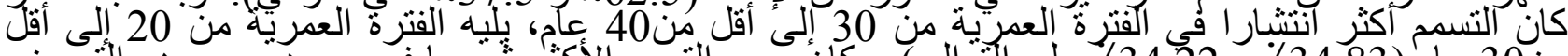

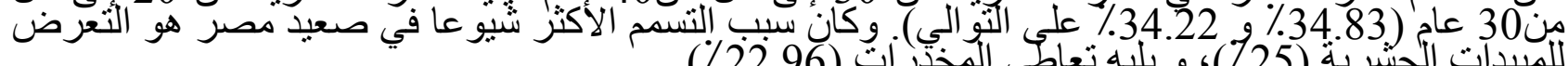

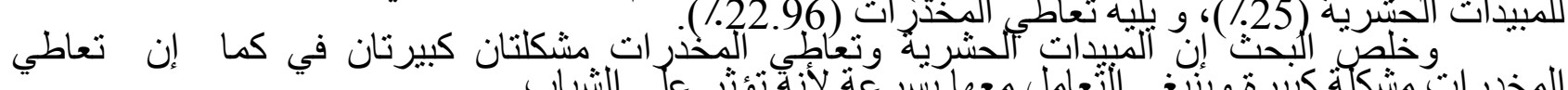

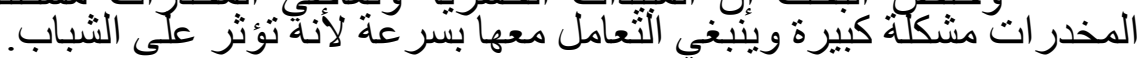

